\title{
Eligibility criterio according to EAU/ESTRO/SIOG guidelines for exclusive iodine-125 brachytherapy for intermediate-risk prostate adenocarcinoma patients: impact on relapse-free survival
}

\author{
Sophie Robin, MD', Sylvie Chabaud, MSc², Anne-Agathe Serre, MD', Béatrice Bringeon, MD³, Sébastien Clippe, MD4,

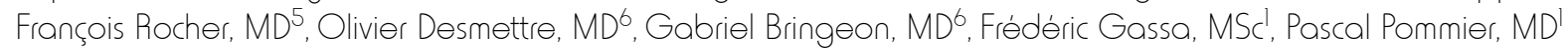 \\ 'Department of Radiation Oncology, Centre Léon Bérard, Lyon, France, ${ }^{2 B}$ Biostatistics Unit, Centre Léon Bérard, Lyon, France, ${ }^{3}$ Department \\ of Anatomopathology, Infirmerie Protestante, Lyon, France, ${ }^{4}$ Department of Radiation Oncology, Centre Marie Curie, Valence, France, \\ ${ }^{5}$ Department of Radiation Oncology, Sainte Marie, Châlon Sur Saône, France, 'bepartment of Urology, Infirmerie Protestante, Lyon, France \\ The research was conducted at the Centre Léon Bérard, 28 Promenade Léa et Napoléon Bullukian, 69008 Lyon, France.
}

\begin{abstract}
Purpose: Iodine-125 ( $\left.{ }^{125} \mathrm{I}\right)$ brachytherapy (BT) alone for intermediate-risk (IR) prostate adenocarcinoma (PCA) is controversial. The purpose of the study was to investigate potential predictive factors in selected IR-PCA patients treated with BT.

Material and methods: Among 547 patients treated with ${ }^{125}$ I BT between 2003 and 2013, 149 IR-PCA cases were selected according to NCCN classification after an additional exclusion of patients with prostate specific antigen (PSA) > $15 \mathrm{ng} / \mathrm{ml}$ and ISUP group 3. A relapse was defined as a biochemical failure, using ASTRO Phoenix definition, or a relapse identified on imaging. Survival curves were estimated with Kaplan-Meier method. Potential prognostic variables including EAU/ ESTRO/SIOG guidelines eligibility criteria were analyzed using univariate and Cox's proportional hazards regression analysis.

Results: Of the 149 IR patients, 112 were classified as favorable, with 69 cases eligible to BT according to EAU/ ESTRO/SIOG guidelines, and 37 patients were identified as unfavorable as per NCCN. Androgen deprivation therapy (ADT) was applied in 6 patients only. Percentage of positive biopsy cores were $\leq 33 \%$ and $\geq 50 \%$ for 119 and 11 patients, respectively. With a median follow-up of 8.5 years, 30 patients experienced a relapse. 10-year overall survival, progression-free survival (PFS), and relapse-free survival (RFS) were 84\% (95\% CI: 75-90\%), 66\% (95\% CI: $56-75 \%)$, and 77\% (95\% CI: 67-84\%), respectively. Failure to meet EAU/ESTRO/SIOG criteria was significantly associated with a lower RFS ( $p=0.0267, \mathrm{HR}=2.37$ [95\% CI: $1.10-5.08 \%]$ ).

Conclusions: Brachytherapy is an effective treatment for selected IR-PCA cases. Patients who were not eligible according to EAU/ESTRO/SIOG guidelines demonstrated a lower RFS.

J Contemp Brachytherapy 2021; 13, 4: 373-386 DOI: https://doi.org/10.5114/jcb.2021.108592

Key words: prostate, brachytherapy, intermediate-risk, guidelines, prognostic criteria.

\section{Purpose}

Low-dose-rate (LDR) brachytherapy (BT) monotherapy has been considered for more than 20 years as the standard of care for patients with low-risk (LR) prostate adenocarcinoma (PCA) [1], with good long-term quality of life [2]. Gradually, guidelines have expanded the use of BT monotherapy to selected intermediate-risk (IR) PCA (Table 1).

In France, a consensus has been raised in 2004 by French urology societies (AFU), radiotherapy (SFRO), medical physics (SFPM), and pathology (SFP) to propose BT alone to selected patients with only one unfavorable factor, including a PSA $10-15 \mathrm{ng} / \mathrm{ml}$ or a Gleason score

(GS) $7(3+4)$, or cT2c [3]. In 2010, the AFU recommendations added a role of magnetic resonance imaging (MRI) to exclude extracapsular extension and evaluate prostate volume, which is the only recommendation to date to mention it and emphasize the importance of the percentage of positive biopsy cores (PBC) for better patients' selection [4].

In Europe, the 2013 EAU/ESTRO/SIOG guidelines specified that BT was an option for patients with cT1-T2a, GS $\leq 7(3+4)$, prostate specific antigen (PSA) $\leq 10 \mathrm{ng} / \mathrm{ml}$, and $\mathrm{PBC} \leq 50 \%$. It was mentioned that in 'well-selected patients' with IR-PCA, long-term data of low-dose-rate brachytherapy were 'promising' [5]. The amended ver-
\end{abstract}


Table 1. Existing guidelines for brachytherapy monotherapy for the treatment of patients with intermediaterisk prostate adenocarcinoma

\begin{tabular}{|c|c|c|c|c|c|c|c|}
\hline & AFU [13] & \multicolumn{2}{|c|}{ EAU/ESTRO/SIOG [1] } & $\mathrm{ABS}[6,7]$ & \multicolumn{2}{|c|}{$\mathrm{ASCO} / \mathrm{CCO}[8]$} & NCCN [9] \\
\hline & $\begin{array}{c}\text { T1-T2 and only } \\
1 \text { unfavorable } \\
\text { criterion }\end{array}$ & & & $\begin{array}{c}\text { Only } \\
1 \text { unfavorable } \\
\text { criterion }\end{array}$ & & & $\begin{array}{c}\text { Only } \\
1 \text { unfavorable } \\
\text { criterion }\end{array}$ \\
\hline Stage & T1-T2 & $\mathrm{cT} 1 \mathrm{~b}$ & $\mathrm{MO}$ & $\mathrm{T} 2 \mathrm{~b}-\mathrm{T} 2 \mathrm{c}$ & \multicolumn{2}{|c|}{ NS } & $\mathrm{T} 2 \mathrm{~b}-\mathrm{T} 2 \mathrm{c}$ \\
\hline PSA (ng/ml) & $10-15$ & \multicolumn{2}{|c|}{$\leq 10$} & $10-20$ & $<10$ & $10-20$ & $10-20$ \\
\hline GS & $7(3+4)$ & 6 & $7(3+4)$ & $7(3+4)$ & $\begin{array}{c}\text { AND } \\
7 \\
\text { (ISUP NS) }\end{array}$ & $\begin{array}{c}\text { AND } \\
6\end{array}$ & $7(3+4)$ \\
\hline$\% \mathrm{PBC}$ & NS & $\begin{array}{l}\text { AND } \\
\leq 50 \%\end{array}$ & $\begin{array}{l}\text { AND } \\
\leq 33 \%\end{array}$ & $\begin{array}{c}\text { AND } \\
\text { PBC }<30 \% \\
\text { without } \\
\text { perineural } \\
\text { invasion }\end{array}$ & & & $\begin{array}{c}\text { AND } \\
P B C<50 \%\end{array}$ \\
\hline
\end{tabular}

AFU - Association Française d'Urologie, EAU/ESTRO/SIOG - European Association of Urology/European Society for Radiotherapy and Oncology/International Society of Geriatric Oncology, ABS - American Brachytherapy Society, ASCO/CCO - American Society of Clinical Oncology/Cancer Care Ontario, NCCN - National Comprehensive Cancer Network, GS - Gleason score, \%PBC-percentage of positive biopsy cores, NS - not specified

sion from 2018 defined a more restrictive consensus on the following eligibility criteria for BT monotherapy: stage cT1b-T2a N0, M0; GS 6 (International Society of Urological Pathology [ISUP] grade 1) with $\mathrm{PBC} \leq 50 \%$, or GS $7(3+4)$ (ISUP grade 2$)$ with $\leq 33 \%$ of invaded biopsies, an initial PSA level of $\leq 10 \mathrm{ng} / \mathrm{ml}[1]$.

The American Brachytherapy Society (ABS) recommended in its 2012 update that "certain IR patients with otherwise low-risk features, such as low-volume disease, predominant pattern 3 , and only one adverse feature can be effectively treated with BT alone" [6]. They relied on a survey of BT practitioners, who would all perform BT alone for IR patients, GS $7(3+4)$ or PSA $10-20 \mathrm{ng} / \mathrm{ml}$, with $\mathrm{CT} 1 \mathrm{c}$ and $\mathrm{PBC} \leq 30 \%$ in the absence of perineural invasion [7]. The American Society of Clinical Oncology/ Cancer Care Ontario Joint Guideline, updated in 2017, suggests that LDR-BT alone may be offered as monotherapy for low-intermediate risk prostate cancer (GS 7, PSA $<10 \mathrm{ng} / \mathrm{ml}$ or GS 6, PSA 10-20 ng/ml) [8]. The National Comprehensive Cancer Network (NCCN) guidelines recommends that $\mathrm{BT}$ alone is an option for patients with very low, low, or favorable IR (FIR) prostate cancer, depending on life expectancy [9].

The aim of this study was to investigate potential predictive factors using EAU guidelines selection criteria in selected IR localized PCA patients treated with iodine-125 ( $\left.{ }^{125} \mathrm{I}\right) \mathrm{BT}$ alone in our center.

\section{Material and methods}

We acquired an IRB approved (R201-004-035) database of patients treated with ${ }^{125} \mathrm{I}$ BT alone for PCA from January 21, 2003 to May 14, 2013 treated at the Centre Léon Bérard Radiotherapy Department.

Patients were classified as IR-PCA according to NCCN classification with at least one unfavorable criterion, such as PSA $\geq 10 \mathrm{ng} / \mathrm{ml}$, ISUP group $>1$ (GS > 6), or $\geq \mathrm{T} 2 \mathrm{~b}$ disease, with the exclusion of $\geq \mathrm{T} 3$ and ISUP group $>3$ and PSA $>20 \mathrm{ng} / \mathrm{ml}$ [9]. The study focused on patients with PSA $\leq 15 \mathrm{ng} / \mathrm{ml}$ and ISUP group $\leq 2$.
Individual patients' data were collected retrospectively from medical records, including initial PSA (iPSA), $\mathrm{T}$ stage (clinical $\mathrm{T}$ stage modified with MRI results when available at the initial staging), histological data (biopsies) GS topography (apex vs. middle lobe vs. base), percentage of PBC, number of anatomic levels (apex, middle lobe, and base) invaded (1 vs. 2 vs. 3), and the use of androgen deprivation therapy (ADT).

In addition, the IR-PCA patients were classified as FIR-PCA (a single IR factor and ISUP group $\leq 2$ and PBC $<50 \%$ ) vs. unfavorable IR (UIR) PCA (other IR patients) disease [10].

FIR patients were divided into 2 groups, those eligible for BT according to the EAU/ESTRO/SIOG guidelines, such as stage T1b-T2a N0, M0, GS 6 (ISUP grade 1) with $\mathrm{PBC} \leq 50 \%$, or GS $7(3+4)$ (ISUP grade 2$)$ with $\leq 33 \%$ of invaded biopsies, initial PSA level of $\leq 10 \mathrm{ng} / \mathrm{ml}$, and those who were not [1].

Prostate BT was performed in all included patients with fully integrated real-time seed treatment (FIRST ${ }^{\mathrm{TM}}$ ) system developed by Nucletron (Elekta-Nucletron, Veenendaal, The Netherlands), that included a 3D transrectal ultrasound computer-controlled rotational system, a robotic seed delivery (SeedSelectron), and an Oncentra seeds treatment planning system [11]. The prescribed dose was $160 \mathrm{~Gy}$ to the prostate while minimizing the dose to the urethra and rectum, according to French and international guidelines.

A relapse was defined as a biochemical failure using ASTRO Phoenix definition or a relapse found on imaging [12]. An imaging with MRI and Cholin positron emission tomography-computed tomography (PET-CT) was recommended in case of biochemical failure, and the site of relapse was specified as local, nodal, or metastatic. Cancers occurring after BT and causes of deaths were recorded.

Median follow-up time was estimated using inverted Kaplan-Meier method. Overall survival (OS) was defined as the time from the date of BT until death resulted from any cause. Relapse-free survival (RFS) was identified as the time between the date of BT and the date of recur- 
rence. Progression-free survival (PFS) was defined as the time between the date of BT and the date of first event (recurrence or death). Patients not known to have presented the event of interest were censored at the date of last information. Survival curves were estimated by Kaplan-Meier method and compared between sub-groups using log-rank test. Potential prognostic parameters were studied using univariate and multivariate Cox's propor- tional hazards regression analysis. Statistical analyses were performed using SAS, version 9.4

\section{Results}

Among 547 patients treated with ${ }^{125}$ I BT between 2003 and 2013, 158 patients were classified as IR-PCA according to the NCCN classification [9]. 149 IR-PCA cases were

Table 2. Description of the population according to risk groups

\begin{tabular}{|c|c|c|c|c|c|}
\hline \multirow[t]{2}{*}{ Criteria } & \multicolumn{2}{|c|}{ Favorable $^{1}$} & \multirow{2}{*}{$\begin{array}{c}\text { Unfavorable }^{1} \\
n=37\end{array}$} & \multirow{2}{*}{$\begin{array}{c}\text { All } \\
n=149\end{array}$} & \multirow[t]{2}{*}{$p$-value } \\
\hline & $\begin{array}{c}\text { Eligible }^{2} \\
n=69\end{array}$ & $\begin{array}{c}\text { Not eligible }{ }^{2} \\
n=43\end{array}$ & & & \\
\hline \multicolumn{6}{|l|}{ Initial PSA (ng/ml) } \\
\hline Missing & 0 & 0 & 0 & 0 & \multirow[t]{4}{*}{$\leq 0.001$} \\
\hline Mean (SD) & $6(1.7)$ & $9.9(3.1)$ & $8.1(3.0)$ & $7.6(3.0)$ & \\
\hline Median (min, max) & $6(1.2,9.3)$ & $10.8(2.8,15.0)$ & $7.5(2.6,14.9)$ & $6.8(1.2,15.0)$ & \\
\hline Q1-Q3 & $5.1-7.1$ & $9.80-11.47$ & $6.16-10.45$ & $5.30-10.40$ & \\
\hline \multicolumn{6}{|l|}{ Initial PSA (ng/ml) } \\
\hline$\leq 10$ & 69 (100\%) & $11(25.6 \%)$ & $26(70.3 \%)$ & $106(71.1 \%)$ & \multirow[t]{2}{*}{$\leq 0.001$} \\
\hline$>10$ & $0(0 \%)$ & $32(74.4 \%)$ & $11(29.7 \%)$ & $43(28.9 \%)$ & \\
\hline \multicolumn{6}{|l|}{ Initial T stage } \\
\hline $\mathrm{T} 1 \mathrm{c}$ & $40(58 \%)$ & $21(48.8 \%)$ & $6(16.2 \%)$ & $67(45 \%)$ & \multirow[t]{4}{*}{$\leq 0.001$} \\
\hline T2a & $29(42 \%)$ & $16(37.2 \%)$ & $4(10.8 \%)$ & $49(32.9 \%)$ & \\
\hline $\mathrm{T} 2 \mathrm{~b}$ & $0(0 \%)$ & $4(9.3 \%)$ & $10(27 \%)$ & $14(9.4 \%)$ & \\
\hline $\mathrm{T} 2 \mathrm{C}$ & $0(0 \%)$ & $2(4.7 \%)$ & $17(45.9 \%)$ & 19 (12.8\%) & \\
\hline \multicolumn{6}{|l|}{ ISUP group } \\
\hline 1 & $0(0 \%)$ & $38(88.4 \%)$ & $8(21.6 \%)$ & $46(30.9 \%)$ & \multirow[t]{2}{*}{$\leq 0.001$} \\
\hline 2 & $69(100 \%)$ & $5(11.6 \%)$ & $29(78.4 \%)$ & $103(69.1 \%)$ & \\
\hline \multicolumn{6}{|c|}{ Number of invaded levels } \\
\hline NA & 10 & 2 & 6 & 18 & \multirow[t]{4}{*}{0.003} \\
\hline 1 & $24(40.7 \%)$ & $16(39 \%)$ & $9(29 \%)$ & $49(37.4 \%)$ & \\
\hline$\underline{2}$ & $30(50.8 \%)$ & $18(43.9 \%)$ & $8(25.8 \%)$ & $56(42.7 \%)$ & \\
\hline 3 & $5(8.5 \%)$ & $7(17.1 \%)$ & $14(45.2 \%)$ & $26(19.8 \%)$ & \\
\hline \multicolumn{6}{|c|}{ Number of performed biopsies } \\
\hline Missing & 0 & 0 & 0 & 0 & \multirow[t]{3}{*}{0.251} \\
\hline Median (min, max) & $12(6,23)$ & $12(6,24)$ & $12(5,24)$ & $12(5,24)$ & \\
\hline Q1-Q3 & $11-13$ & $10-15$ & $10-13$ & $10-14$ & \\
\hline \multicolumn{5}{|l|}{ Percentage of PBC } & \multirow[t]{3}{*}{0.001} \\
\hline Missing & 0 & 0 & 0 & 0 & \\
\hline Median (min, max) & $16.7(5.6,30.8)$ & $25.0(5.6,46.2)$ & $33.3(7.1,91.7)$ & $21.4(5.6,91.7)$ & \\
\hline Q1-Q3 & $10.0-25.0$ & $12.5-33.3$ & $20.0-50.0$ & $11.1-30.0$ & \multirow[t]{4}{*}{0.001} \\
\hline$\leq 33.0 \%$ & $69(100 \%)$ & $32(74.4 \%)$ & $18(48.6 \%)$ & $119(79.9 \%)$ & \\
\hline $33.0-50 \%$ & $0(0 \%)$ & $11(25.6 \%)$ & $8(21.6 \%)$ & 19 (12.8\%) & \\
\hline$\geq 50 \%$ & $0(0 \%)$ & $0(0 \%)$ & $11(29.7 \%)$ & $11(7.4 \%)$ & \\
\hline \multicolumn{6}{|l|}{ Topography of the PBC } \\
\hline NA & 10 & 2 & 6 & 18 & \\
\hline Base & $37(62.7 \%)$ & $22(53.7 \%)$ & $21(67.7 \%)$ & 80 (61.1\%) & 0.463 \\
\hline Middle & 35 (59.3\%) & $28(68.3 \%)$ & $22(71 \%)$ & 85 (64.9\%) & 0.500 \\
\hline Apex & 27 (45.8\%) & $23(56.1 \%)$ & 24 (77.4\%) & 74 (56.5\%) & 0.015 \\
\hline
\end{tabular}

${ }^{1}$ According to Zumsteg classification, ${ }^{2}$ To brachytherapy according to the European Association of Urology/European Society for Radiotherapy and Oncology/International Society of Geriatric Oncology (EAU/ESTRO/SIOG) guidelines

$P B C$ - positive biopsy cores, NA - not available 
analyzed after exclusion of patients with PSA $>15 \mathrm{ng} / \mathrm{ml}$ (3 patients) and ISUP group 3 (6 patients), representing $27.2 \%$ of all patients treated during this period. Description of study population according to risk group is pre-

A

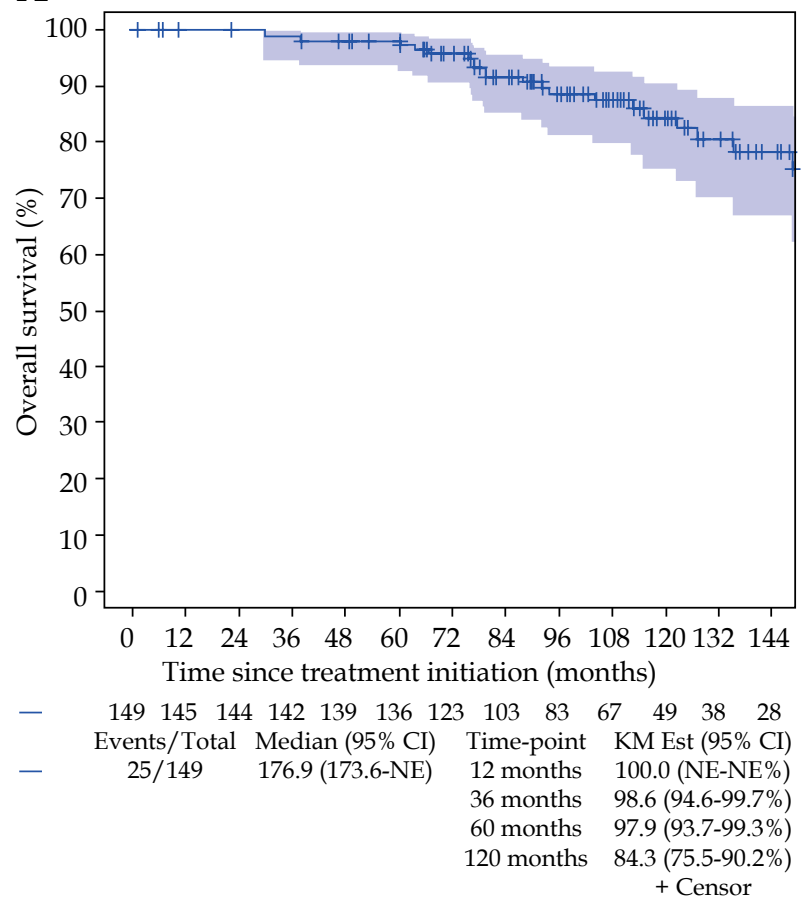

C

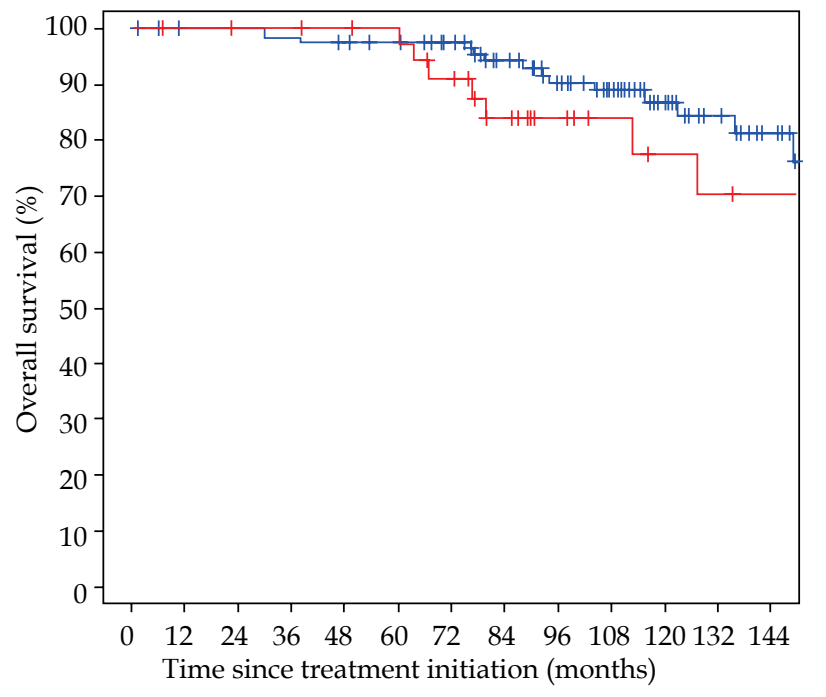

$\begin{array}{llllllllllllll}- \text { FIR } & 112 & 109 & 109 & 107 & 105 & 103 & 94 & 81 & 67 & 54 & 38 & 28 & 19\end{array}$

$\begin{array}{llllllllllllll}-\mathrm{UIR} & 37 & 36 & 35 & 35 & 34 & 33 & 29 & 22 & 16 & 13 & 11 & 10 & 9\end{array}$

$\begin{array}{cccc} & \text { Events/Total } & \text { Median (95\% CI) } & \text { HR (95\% CI) } \\ \text { - FIR } & 17 / 112 & 176.9(173.6-\mathrm{NE}) & \text { Reference }\end{array}$

$\begin{array}{lccc}\text { - UIR } & 8 / 37 & \text { NE (127.1-NE) } & 1.51(0.65-3.51)\end{array}$

Log rank $p$-value: 0.3356 sented in Table 2. The median age at BT was 69 years old (range, 49-82 years old), with interquartile range (IQR) of 62-74 years. No patient received transurethral prostate resection before BT. Only 6 patients $(4 \%)$ obtained

B

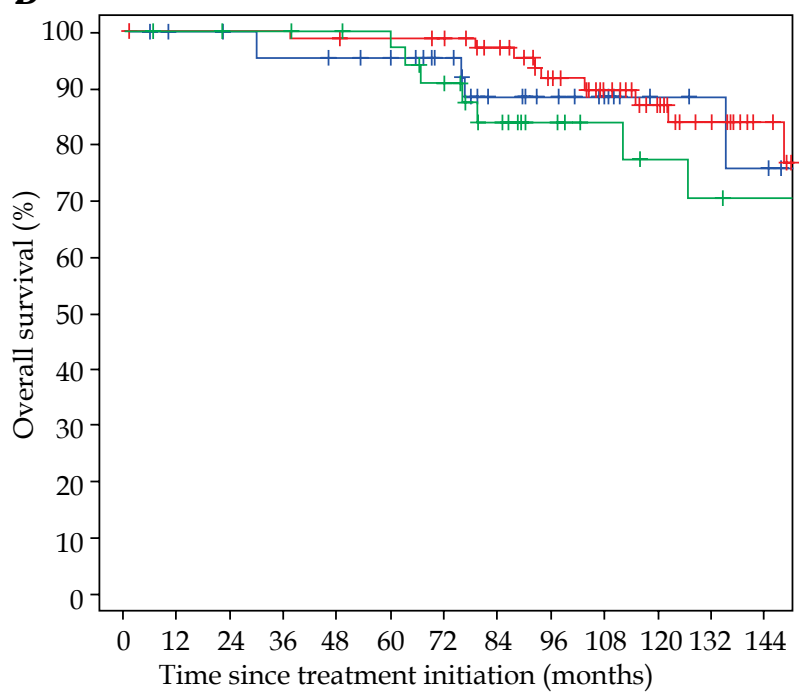

- FIR not eligible

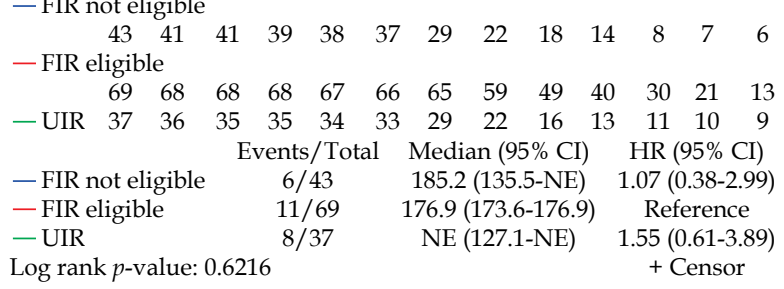

D

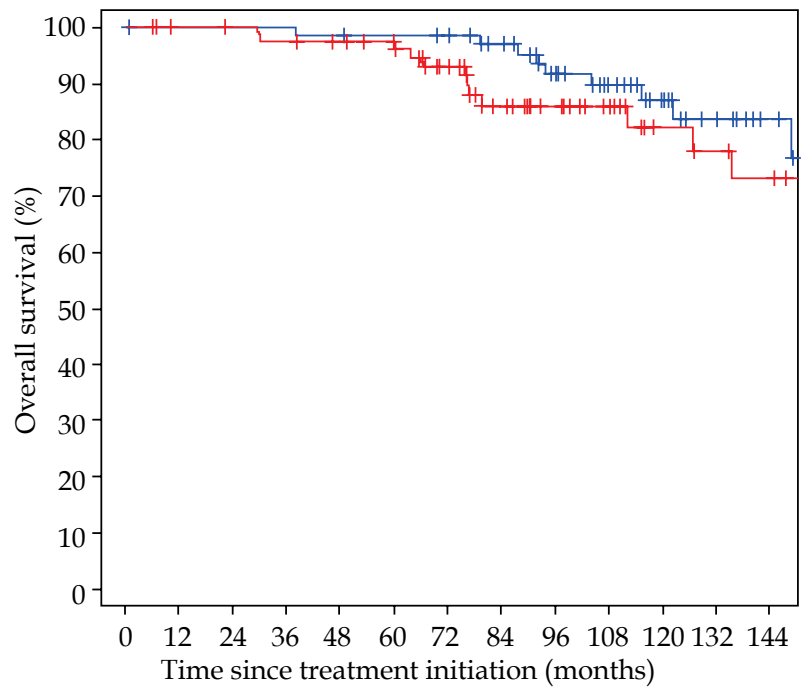

- FIR eligible

$$
\begin{array}{lllllllllllll}
69 & 68 & 68 & 68 & 67 & 66 & 65 & 59 & 49 & 40 & 30 & 21 & 13
\end{array}
$$

- FIR not eligible + UIR

$\begin{array}{lllllllllllll}80 & 77 & 76 & 74 & 72 & 70 & 58 & 44 & 34 & 27 & 19 & 17 & 15\end{array}$

$\begin{array}{cccc} & \text { Events/Total } & \text { Median (95\% CI) } & \text { HR }(95 \% \mathrm{CI}) \\ \text { - FIR eligible } & 11 / 69 & 176.9(173.6-176.9) & \text { Reference }\end{array}$

- FIR not eligible + UIR $14 / 80 \quad 185.2(161.3-\mathrm{NE}) \quad 1.31(0.58-2.95)$ Log rank $p$-value: 0.5188 + Censor

Fig. 1. Kaplan-Meier estimate of overall survival for the entire cohort (A); for eligible FIR vs. not eligible FIR vs. UIR (B); for FIR vs. UIR (C); and for FIR eligible vs. FIR not eligible or UIR (D)

FIR - favorable intermediate-risk, eligible - eligible for brachytherapy according to the EAU guidelines, UIR - unfavorable intermediate-risk 
short-term ADT, which started before BT, including 4 patients, who received luteinizing hormone-releasing hormone (LHRH) agonists (median, 6 months; IQR, 5.256 months), and 3 patients, who received non-steroid anti-

A

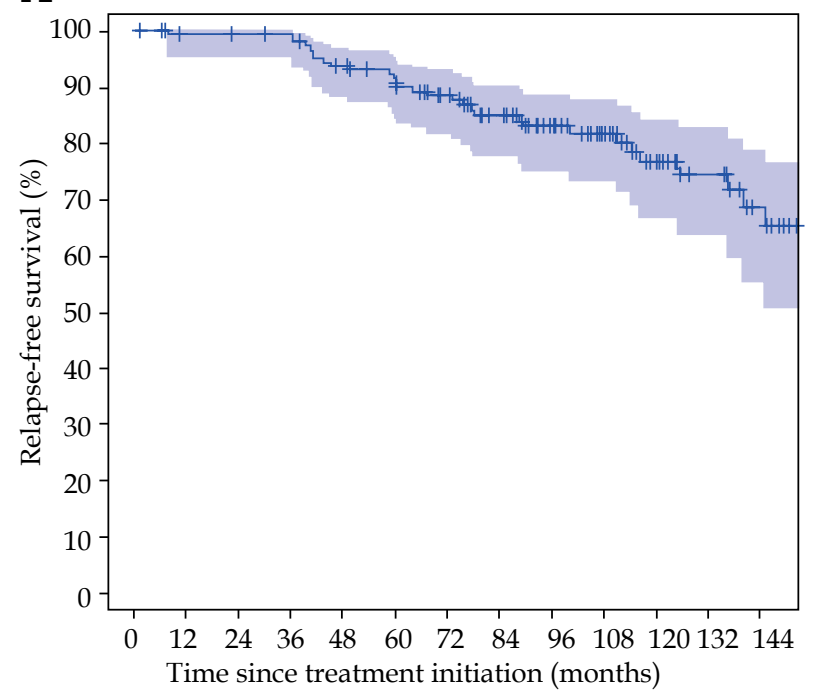

$\begin{array}{llllllllllllll}- & 149 & 144 & 143 & 141 & 130 & 124 & 109 & 89 & 72 & 58 & 40 & 30 & 20\end{array}$

Events/Total Median (95\% CI) Time-point KM Est (95\% CI)

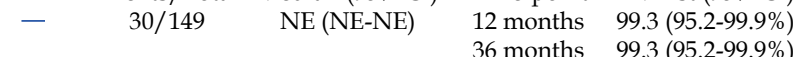

60 months $91.4(85.4-95.0 \%)$

120 months $76.6(66.8-83.9 \%)$

+ Censor

C

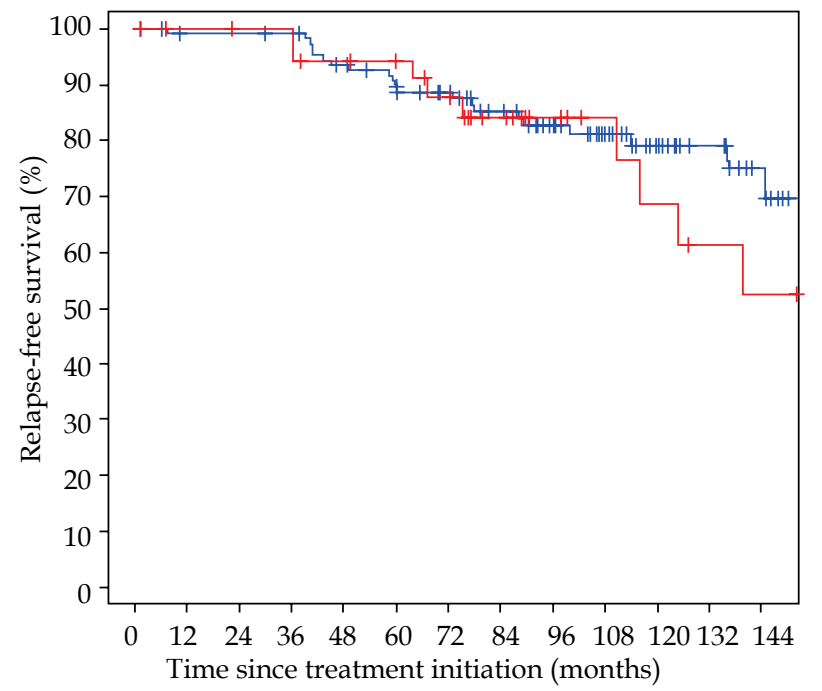

$\begin{array}{llllllllllllll}\text { - FIR } & 112 & 108 & 108 & 106 & 98 & 93 & 83 & 70 & 58 & 47 & 31 & 23 & 14\end{array}$

$\begin{array}{llllllllllllll}-\mathrm{UIR} & 37 & 36 & 35 & 35 & 32 & 31 & 26 & 19 & 14 & 11 & 9 & 7 & 6\end{array}$

$\begin{array}{cccc} & \text { Events/Total } & \text { Median (95\% CI) } & \text { HR (95\% CI) } \\ \text { - FIR } & 21 / 112 & \text { NE (NE-NE) } & \text { Reference }\end{array}$

$\begin{array}{lccc}- \text { UIR } & 9 / 37 & \text { NE (116.1-NE) } & 1.38(0.63-3.02)\end{array}$

Log rank $p$-value: 0.4171 androgens (median, 120 days; IQR, 75-120 days). Lots of information from pathology reports were missing to study perineural invasion and capsular effraction. MRI was available at the initial staging for 89 patients only.

\section{B}

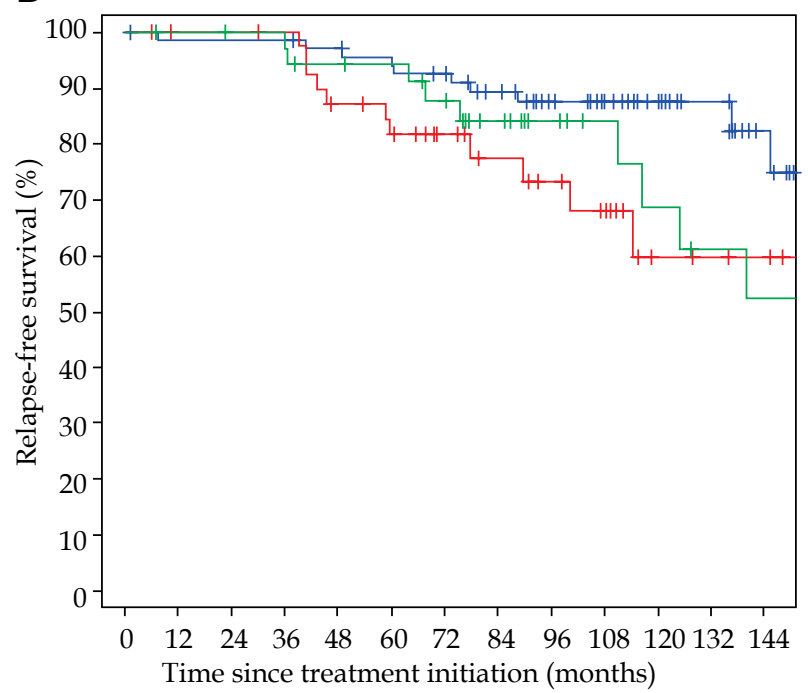
- FIR eligible

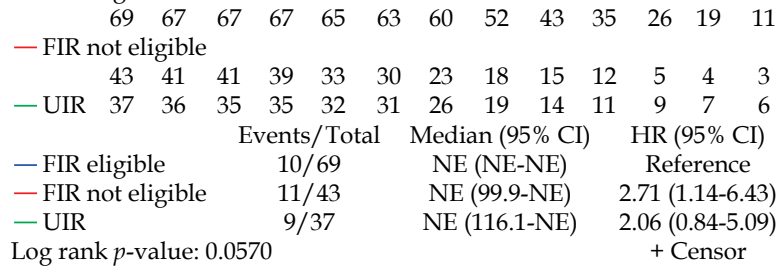

D

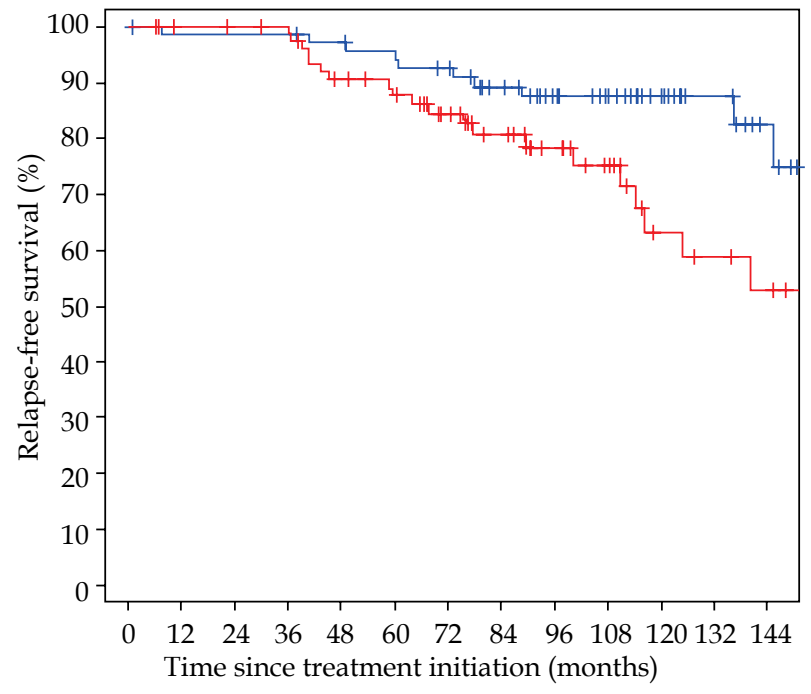

- FIR eligible

- FIR not eligible + UIR

$\begin{array}{lllllllllllll}80 & 77 & 76 & 74 & 65 & 61 & 49 & 37 & 29 & 23 & 14 & 11 & 9\end{array}$

$\begin{array}{lccc} & \text { Events/Total } & \text { Median }(95 \% \mathrm{CI}) & \mathrm{HR}(95 \% \mathrm{CI}) \\ \text { - FIR eligible } & 10 / 69 & \mathrm{NE}(\mathrm{NE}-\mathrm{NE}) & \end{array}$

— FIR not eligible + UIR $\quad 20 / 80 \quad$ NE (116.1-NE) $\quad 2.37$ (1.10-5.08)

Log rank $p$-value: 0.0224

Fig. 2. Kaplan-Meier estimate of relapse-free survival for the entire cohort (A); for eligible FIR vs. not eligible FIR vs. UIR (B); for FIR vs. UIR (C); and for FIR eligible vs. FIR not eligible or UIR (D)

FIR - favorable intermediate-risk, eligible - eligible for brachytherapy according to the EAU guidelines, UIR-unfavorable intermediate-risk 


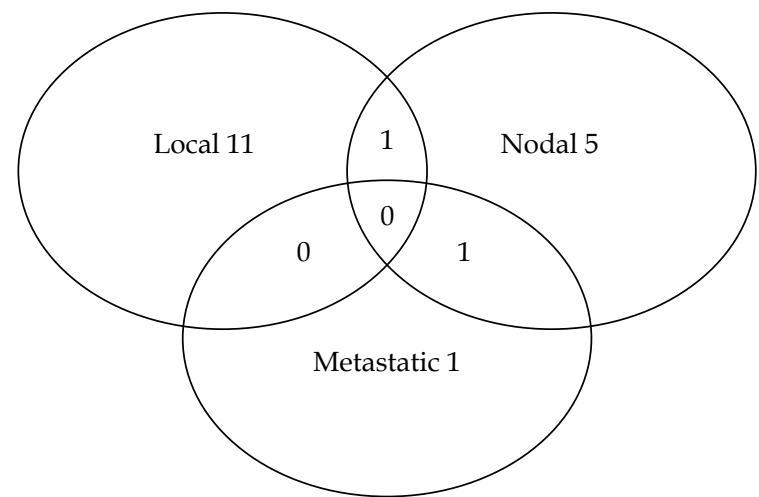

Fig. 3. Venn diagram of relapses for patients with imaging

In total, 112 patients $(75.2 \%)$ were classified as FIR-PCA, including 69 patients (46.3\%) eligible to BT according to the EAU/ESTRO/SIOG guidelines. Thirty-seven patients $(24.8 \%)$ presented UIR prostate cancer.

The median follow-up was 102 months (8.5 years), ranging from 1 to 190 months (15.8 years) (IQR, 77-132 months). One patient was lost to follow-up after the scheduled 6-week visit. The follow-up $\geq 5$ years for 136 patients $(91.3 \%)$ was obtained.

The 5-year and 10-year OS were 98\% (95\% CI: 94-99\%) and $84 \%$ (95\% CI: 75-90\%), respectively. The median OS was 176.9 months (Figure 1). Of the 25 patients who deceased, only one patient died of a metastatic progression of prostate cancer, whereas 13 patients died of other cancers and 7 of intercurrent causes. No patient died of BT toxicity, and for 4 patients, the cause of death was unknown. Twenty-two (14.8\%) patients developed another cancer during the follow-up after BT. The 5-year and 10-year RFSs were 91\% (95\% CI: 85-95\%) and 77\% (95\% CI: $67-84 \%)$, respectively (Figure 2). Thirty patients (20.1\%) experienced a relapse. The median time to a relapse was 65 months, ranging from 7 to 144 months (IQR, 43.5-96.5 months). An imaging was performed in 21 patients. The distribution of the first site of a relapse among the patients is presented in Figure 3. Two patients experienced no relapse shown on imaging and have been monitored. A local relapse was histologically proven in 8 patients (negative biopsy in 1 and biopsies not performed in 3 cases). In addition, one patient among the 9 patients, who did not benefit from an imaging exam had a proven prostate relapse after a series of biopsies.

The 5-year and 10-year PFSs were 89\% (95\% CI: 83$94 \%$ ) and $66 \%$ (95\% CI: 56-75\%), respectively (Figure 4).

There was no statistically significant difference in RFS between patients with FIR- and patients with UIRPCA, but a trend to a difference between the 3 groups when divided the FIR group in 'eligible' vs. 'non-eligible' $(p=0.057)$. The difference was significant when comparing FIR-PCAs eligible to BT according to the EAU/ ESTRO/SIOG guidelines (10 relapses/69) and other IR-PCA patients (20 relapses $/ 80)(p=0.0224)$. RFS curves for patients with FIR-PCA not eligible to BT according to the EAU/ESTRO/SIOG guidelines and UIR-PCAs seemed to overlap (Figure 2).

The results of univariate analysis for RFS is presented in Table 3. Failure to meet the EAU/ESTRO/SIOG crite- ria was significantly associated with a lower RFS, with $p=0.0267$ and $\mathrm{HR}=2.37$ (95\% CI: $1.10-5.08 \%)$. No multivariate analyses were conducted, as no other variables were statistically significantly associated with RFS.

Statistically, there was no significant difference in OS and PFS between the 3 groups. However, there was a trend to a difference in PFS between the patients with FIR-PCA eligible to BT according to the EAU/ESTRO/ SIOG guidelines and the other patients $(p=0.0608)$ (Figure 4).

\section{Discussion}

Exclusive BT, as a sole radiotherapy modality, is a well-established treatment for low-risk PCA [1, 8, 9, 13], but there are some discrepancies within the guidelines for appropriate selection criteria in the IR group of patients $[1,6,8,9,13]$ (Table 1$)$. Five studies have only investigated patients with IR-PCA (Table 4) [14-18].

Seventeen studies reported series of exclusive brachytherapy, including IR patients but mixed with low[19-23] and high-risk (HR) patients [24-35], with a variable rate of patients receiving ADT up to $58.2 \%$ [19-35] (Table 5).

While concerning separately the initial criteria of the disease, iPSA is an independent predictive factor in multivariate analysis for RFS [28, 29, 32-35], distant metastasis-free survival (DMFS) [29], and OS [30]. In particular, for IR patients, iPSA is an independent risk factor for a biochemical relapse [14, 15].

Gleason score is another prognostic factor associated with RFS [29, 34, 35], DMFS, and OS [29]. The effect of predominant Gleason grade $(3+4$ vs. $4+3)$ on outcomes of patients treated with exclusive BT, remains unclear. In Routman et al. study, GS $4+3$ was a factor most strongly associated with biochemical failure $(p<0.001)$, incidence of distant metastasis $(p=0.003)$, and PCSM $(p<0.001)$. However, no difference in outcomes between patients with GS $3+3$ vs. $3+4$ was observed [19]. In a study by Burdick et al., a significant difference was found between a 5-year RFS in patients with predominant grade $3(88 \%)$ vs. predominant grade $4(76 \%)(p=0.0231)$ in 127 IR and HR patients treated with BT [36]. Moreover, in Herbert et al. study, especially for IR patients, GS 7 was an independent risk factor for a biochemical relapse $(p=0.0035)$ in multivariate analysis, but there was no difference in estimated 5-year RFS between GS $3+4$ vs. GS $4+3$ (95\% and $94 \%$, respectively; $p=0.791$ ) [14]. Munro et al. reported no significant difference between GS $3+4(82.1 \%)$ and GS $4+3(56.3 \%)(p=0.67)$ groups [16].

Analyzing combined criteria, in the IR group defined by a PSA $10.1-20 \mathrm{ng} / \mathrm{ml}$ and GS 6, had a 2.5-fold increased risk of biochemical failure compared to the GS 7 and PSA $<10 \mathrm{ng} / \mathrm{ml}$ group $(p=0.0002)$ [14].

Up till now, no study has explored the prognostic role of PBC percentage, specifically among IR patients treated with BT alone. The validation of prognostic utility of the sub-classification of IR patients between FIR and UIR suggests a potential impact of $\mathrm{PBC}<50 \%[17,24]$. In Frank et al. study, patients with GS 7, PSA $<10 \mathrm{ng} / \mathrm{ml}$, and $\mathrm{PBC} \leq 35 \%$ were eligible to BT alone [18]. In Kindts et al. 
research, $\mathrm{PBC}>50 \%$ significantly impacted local failure $(p=0.02)$ [37]. Moreover, Nurani et al. observed that PBC $\geq 50 \%$ was an independent predictor of poorer RFS in patients with IR- or HR-PCA $(92 \%$ vs. $81 \%$ at 5 years for

A

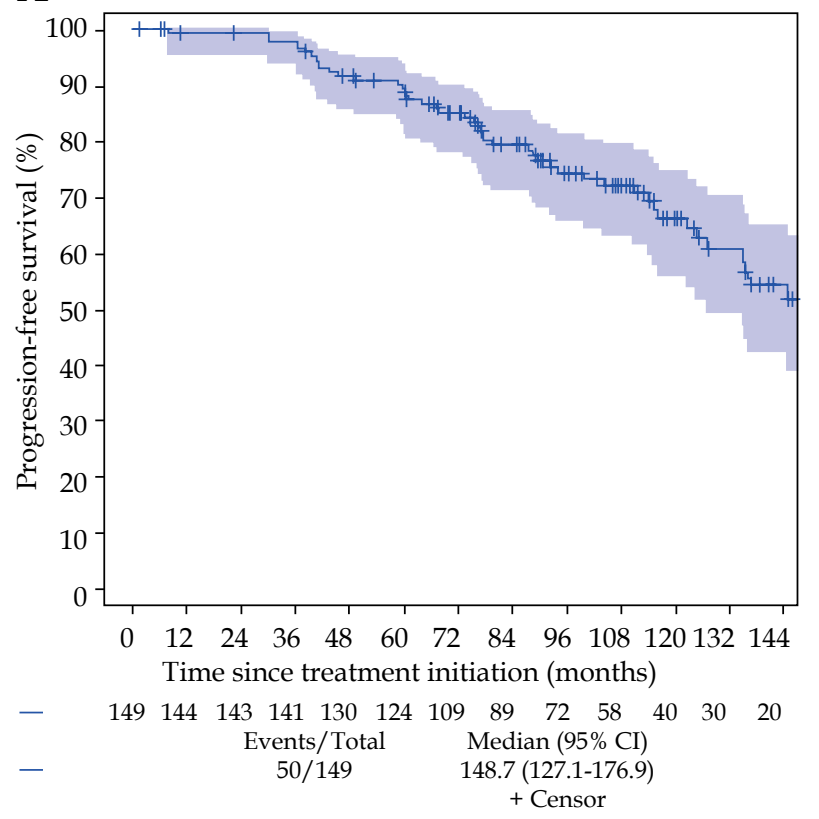

C

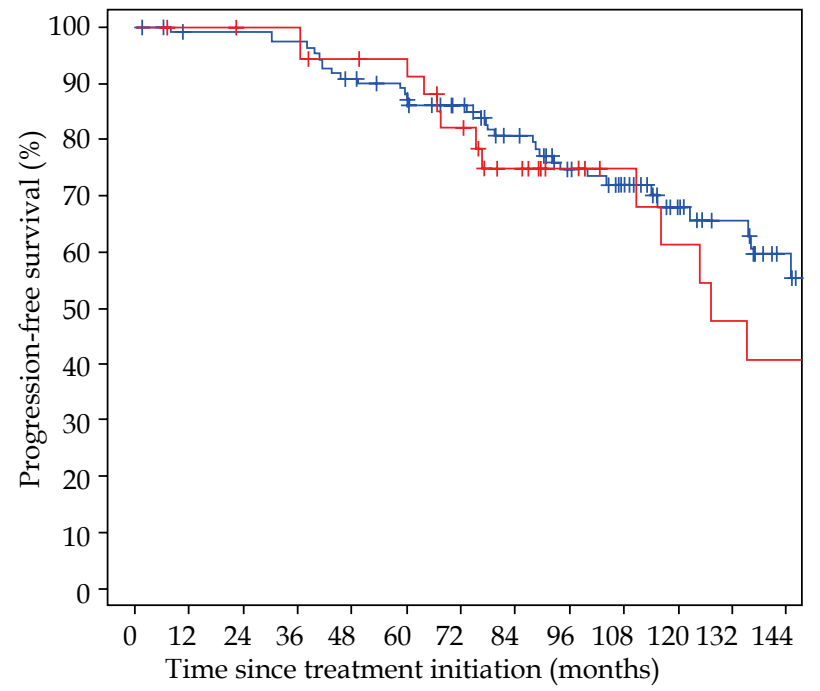

$\begin{array}{llllllllllllll}\text { - FIR } & 112 & 108 & 108 & 106 & 98 & 93 & 83 & 70 & 58 & 47 & 31 & 23 & 14\end{array}$

$\begin{array}{llllllllllllll}-\mathrm{UIR} & 37 & 36 & 35 & 35 & 32 & 31 & 26 & 19 & 14 & 11 & 9 & 7 & 6\end{array}$

$\begin{array}{lccc} & \text { Events/Total } & \text { Median }(95 \% \mathrm{CI}) & \text { HR }(95 \% \mathrm{CI}) \\ \text { - FIR } & 36 / 112 & 148.7(135.5-176.9) & \text { Reference }\end{array}$

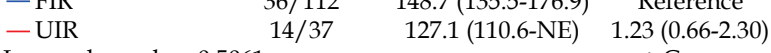

Log rank $p$-value: 0.5061 patients with $\mathrm{PBC}<50 \%$ vs. $\geq 50 \%$; $p=0.009)$. However, a higher dose delivered to the prostate $\left(\mathrm{D}_{90 \%}\right)$ minimized adverse effect of $\mathrm{PBC} \geq 50 \%$ on biochemical failure [38]. Similarly, the percentage of $\mathrm{PBC}$ is probably a prognostic

B

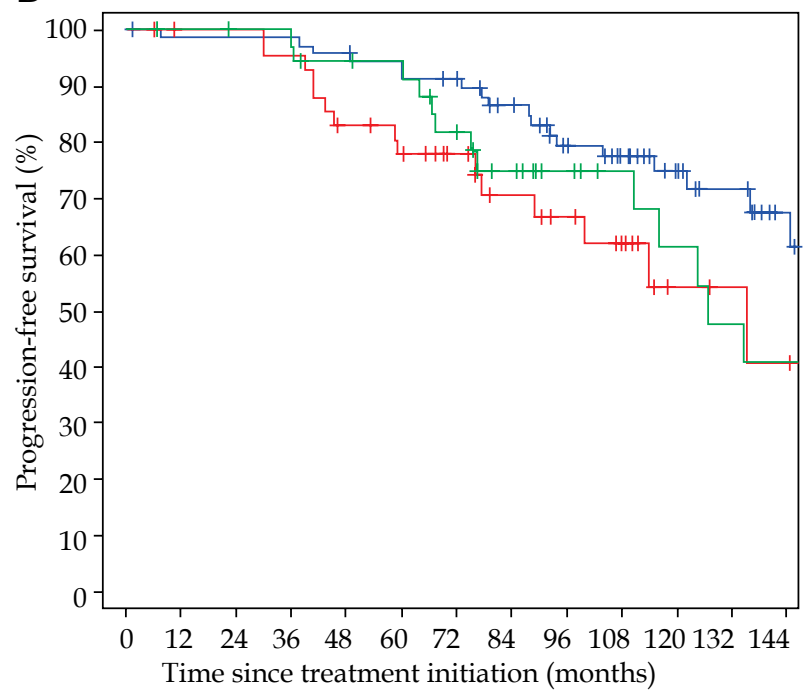

- FIR eligible

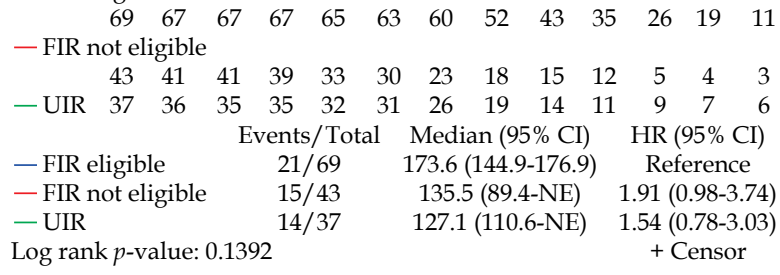

D

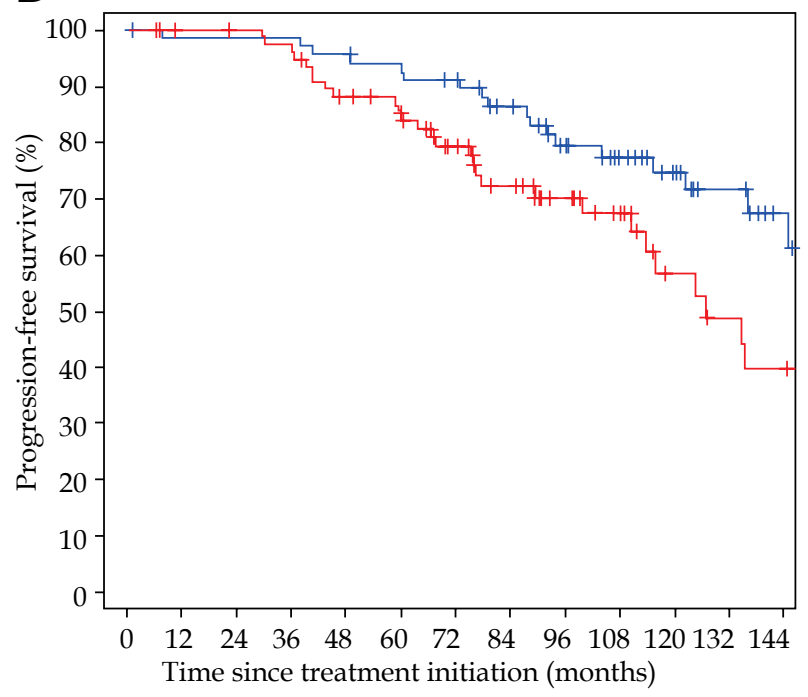

- FIR eligible

- FIR not eligible + UIR

$\begin{array}{lllllllllllll}80 & 77 & 76 & 74 & 65 & 61 & 49 & 37 & 29 & 23 & 14 & 11 & 9\end{array}$

$\begin{array}{ccccc} & \text { Events/Total Median (95\% CI) } & \text { HR (95\% CI) } \\ \text { _ FIR eligible } & 21 / 69 & 173.6(144.9-176.9) & \end{array}$

$\begin{array}{llcc}\text { - FIR eligible } & 21 / 69 & 173.6(144.9-176.9) & \text { Reference } \\ \text { - FIR not eligible + UIR } & 29 / 80 & 127.1(110.6-\mathrm{NE}) & 1.71(0.97-3.01\end{array}$

Log rank $p$-value: 0.0608 + Censor

Fig. 4. Kaplan-Meier estimate of progression-free survival for the entire cohort (A); for eligible FIR vs. not eligible FIR vs. UIR (B); for FIR vs. UIR (C); and for FIR eligible vs. FIR not eligible or UIR (D)

FIR - favorable intermediate-risk, eligible - eligible for brachytherapy according to the EAU guidelines, UIR - unfavorable intermediate-risk 
Table 3. Univariate analysis associated with relapse-free survival

\begin{tabular}{|c|c|c|c|}
\hline Factors & Events/n & $\begin{array}{c}\text { Hazard ratio } \\
(95 \% \mathrm{Cl})\end{array}$ & $p$-value \\
\hline Initial PSA & & & 0.3820 \\
\hline$\leq 10 \mathrm{ng} / \mathrm{ml}$ & 20/106 & 1.00 & \\
\hline$>10 \mathrm{ng} / \mathrm{ml}$ & $10 / 43$ & $1.40(0.66-3.00)$ & \\
\hline T stage & & & 0.1407 \\
\hline T1c-T2a & $21 / 116$ & 1.00 & \\
\hline $\mathrm{T} 2 \mathrm{~b}-\mathrm{T} 2 \mathrm{c}$ & $9 / 33$ & $1.80(0.82-3.94)$ & \\
\hline ISUP grade & & & 0.1878 \\
\hline 1 & $11 / 46$ & 1.00 & \\
\hline 2 & $19 / 103$ & $0.61(0.29-1.28)$ & \\
\hline Biopsies + at the base & & & 0.5992 \\
\hline No & $13 / 51$ & 1.00 & \\
\hline Yes & $16 / 80$ & $0.82(0.39-1.71)$ & \\
\hline $\begin{array}{l}\text { Biopsies + at the middle } \\
\text { lobe }\end{array}$ & & & 0.8660 \\
\hline No & $12 / 46$ & 1.00 & \\
\hline Yes & $17 / 85$ & $0.94(0.44-1.99)$ & \\
\hline Biopsies + at the apex & & & 0.8568 \\
\hline No & $13 / 57$ & 1.00 & \\
\hline Yes & $16 / 74$ & $0.93(0.45-1.95)$ & \\
\hline $\begin{array}{l}\text { Number of invaded levels } \\
\text { on biopsies (apex/middle } \\
\text { lobe/base) }\end{array}$ & & & 0.5637 \\
\hline 1 & $14 / 49$ & 1.00 & \\
\hline 2 & $10 / 56$ & $0.64(0.28-1.45)$ & \\
\hline 3 & $5 / 26$ & $0.85(0.30-2.39)$ & \\
\hline $\begin{array}{l}\text { Percentage of positive } \\
\text { biopsy cores }\end{array}$ & & & 0.2452 \\
\hline$\leq 33 \%$ & $22 / 119$ & 1.00 & \\
\hline $33-50 \%$ & $6 / 19$ & $2.18(0.88-5.40)$ & \\
\hline$\geq 50 \%$ & $2 / 11$ & $1.15(0.27-4.91)$ & \\
\hline$\leq 33 \%$ & $22 / 119$ & 1.00 & 0.1653 \\
\hline$>33 \%$ & $8 / 30$ & $1.78(0.79-4.01)$ & \\
\hline$<50 \%$ & $28 / 138$ & 1.00 & 0.9812 \\
\hline$\geq 50 \%$ & $2 / 11$ & $1.02(0.24-4.28)$ & \\
\hline $\begin{array}{l}\text { Zumsteg/NCCN } \\
\text { classification }\end{array}$ & & & 0.4189 \\
\hline $\mathrm{FIR}^{1}$ & $21 / 112$ & 1.00 & \\
\hline$U \mathrm{UR}^{2}$ & $9 / 37$ & $1.38(0.63-3.02)$ & \\
\hline $\begin{array}{l}\text { EAU/ESTRO/SIOG } \\
\text { guidelines }\end{array}$ & & & 0.0682 \\
\hline FIR $^{1}$ eligible $^{3}$ & $10 / 69$ & 1.00 & \\
\hline FIR $^{1}$ not eligible ${ }^{3}$ & $11 / 43$ & $2.71(1.14-6.43)$ & \\
\hline$U \mathrm{UR}^{2}$ & $9 / 37$ & $2.06(0.84-5.09)$ & \\
\hline FIR $^{1}$ eligible $^{3}$ & $10 / 69$ & 1.00 & 0.0267 \\
\hline FIR $^{1}$ not eligible ${ }^{3}+U R^{2}$ & $20 / 80$ & $2.37(1.10-5.08)$ & \\
\hline
\end{tabular}

${ }^{1}$ Favorable intermediate-risk according to Zumsteg classification, '2Unfavorable intermediate-risk according to Zumsteg classification, ${ }^{3} T o$ brachytherapy according to European Association of Urology/European Society for Radiotherapy and Oncology/International Society of Geriatric Oncology (EAU/ESTRO/SIOG) guidelines NCCN - National Comprehensive Cancer Network factor in LR patients. In two studies, with majority of LRPCA patients, a 5 -year RFS was $95 \%$ vs. $63 \%$ in patients with less versus more than 50\% PBC disease $(p<0.0001)$, and $\mathrm{PBC}$ greater than median $(27 \%)$ was an independent predictor of biochemical failure $(p=0.011)[39,40]$.

The strength of our study is the selected homogeneous IR-PCA population, treated with BT alone (except only $4 \%$ of patients receiving short-term ADT), with a long-term follow-up. All potential prognostic factors were available (including percentage of PBC), but not $\mathrm{D}_{90 \%}$. Due to the retrospective nature of the present study, MRI was performed at the initial staging for only $59.7 \%$ of patients. Moreover, not all patients, who presented a relapse defined as a biochemical failure using the ASTRO Phoenix definition or a relapse identified on imaging had a histological confirmation of recurrence. Therefore, we decided to consider the most unfavorable hypothesis considering that all these patients had suffered a recurrence.

The RFS, PFS, and OS results are consistent with the existing literature regarding IR patients. As for prognostic factors, we did not find a prognostic role of isolated standard disease criterion (iPSA, T stage, GS), neither that of Zumsteg IR sub-classification, nor that of the numbers of UIR factors, as described in the literature, possibly due to a lack of power.

The incidence of the percentage of PBC alone is also not significantly associated with RFS, but it becomes meaningful when associated with other selection criteria proposed by the EAU guidelines, thus validating this European proposal.

\section{Conclusions}

In our study, we have shown that eligibility criteria of ${ }^{125} \mathrm{I}$ BT alone according to the EAU/ESTRO/SIOG guidelines among IR patients are the prognostic criteria. Patients who were not eligible according to the EAU/ ESTRO/SIOG guidelines had a lower RFS.

\section{Acknowledgements}

Thanks to Sophie King for her contribution to this work.

\section{Disclosure}

The authors report no conflict of interest. 


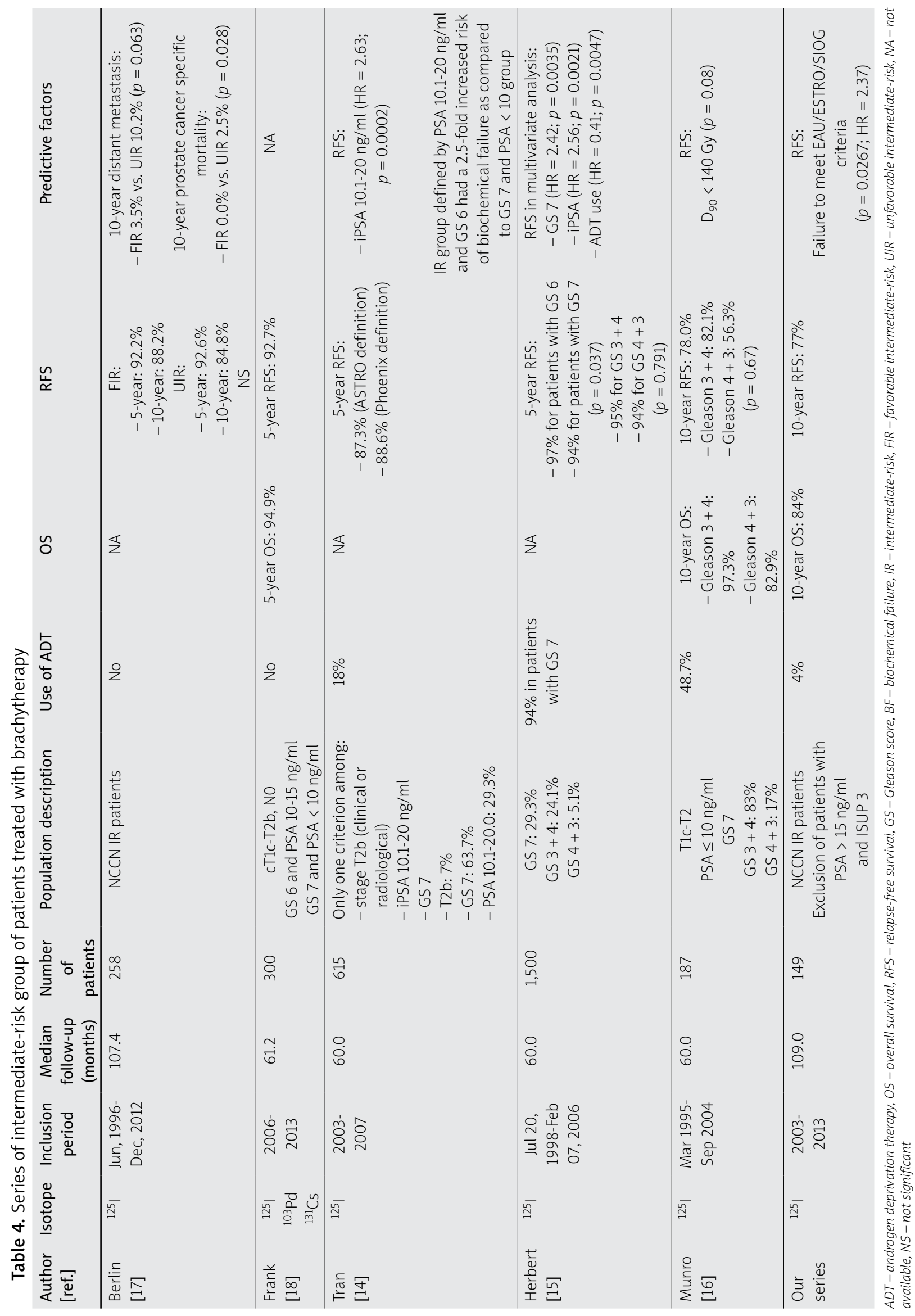




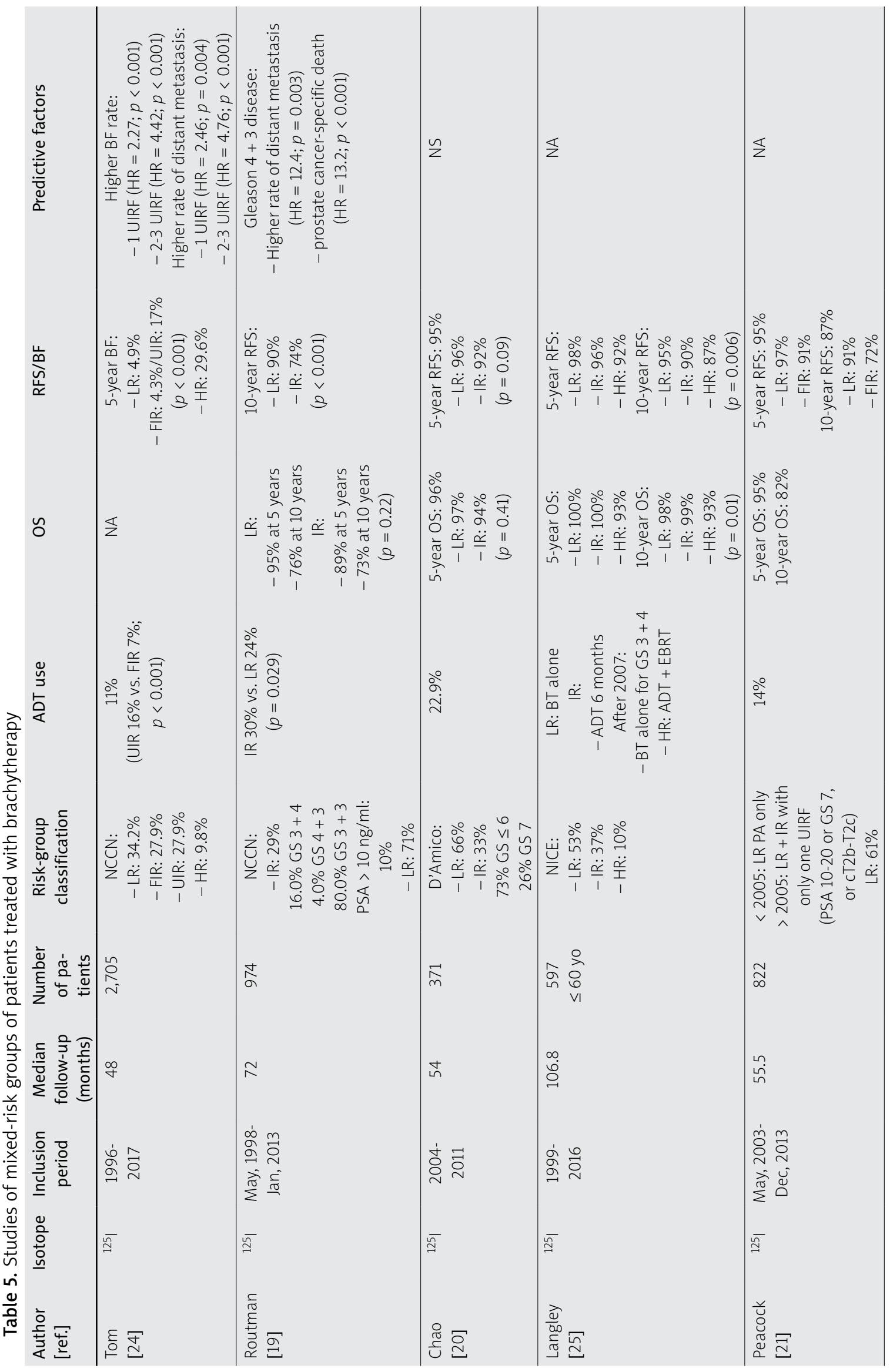




\begin{tabular}{|c|c|c|c|c|c|c|}
\hline 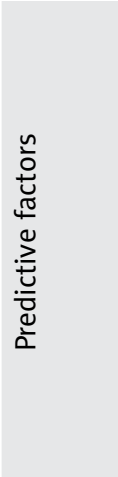 & 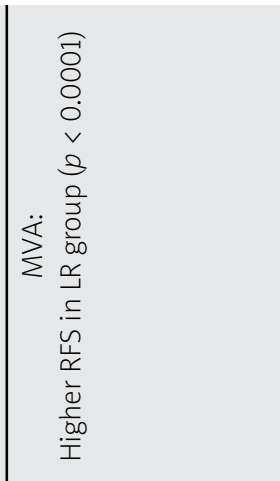 & $\tilde{z}$ & 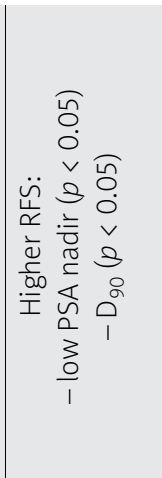 & 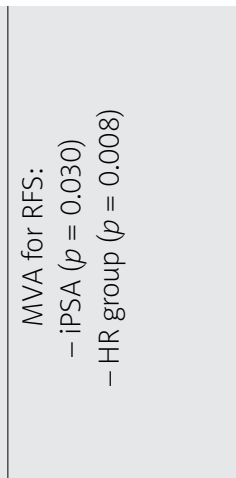 & 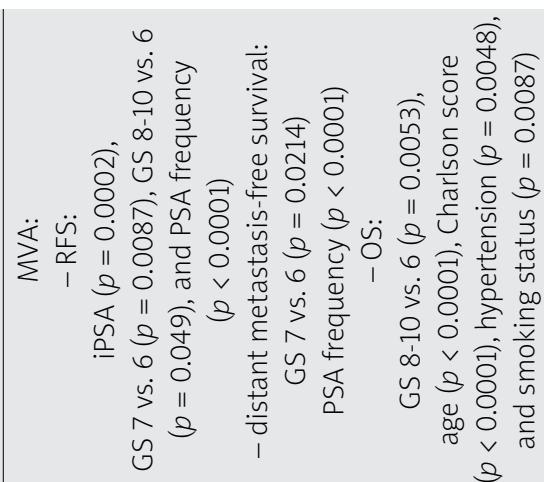 & 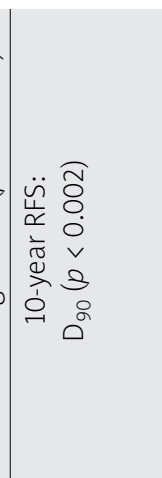 \\
\hline 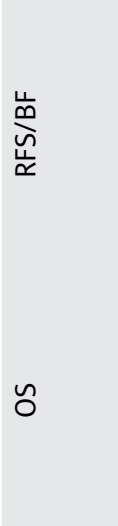 & 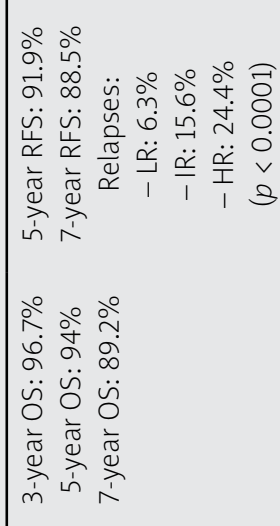 & 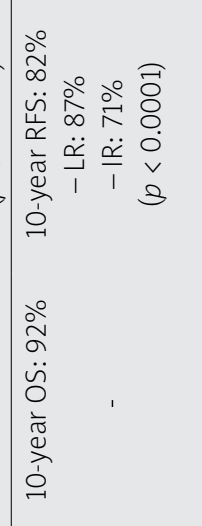 & 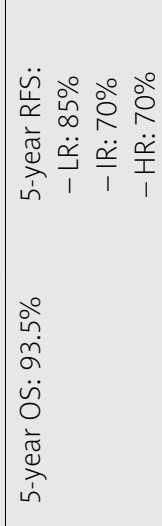 & 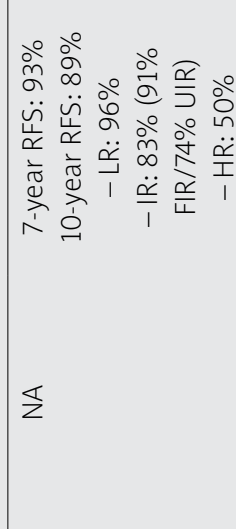 & 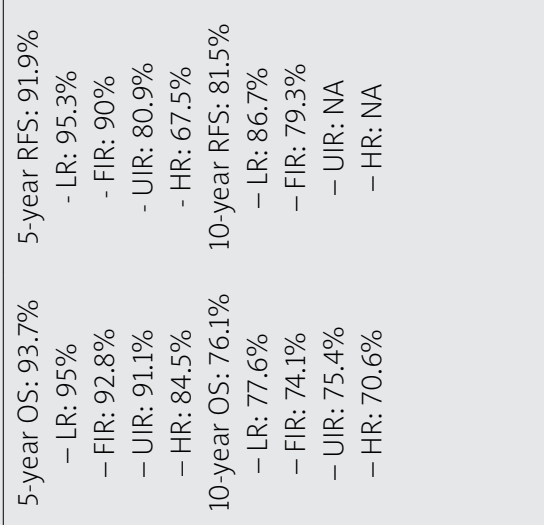 & 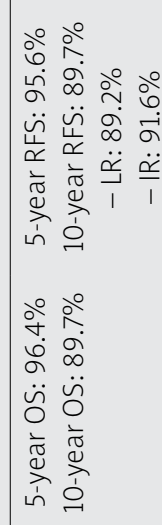 \\
\hline $\begin{array}{l}\stackrel{y}{y} \\
5 \\
\frac{1}{\alpha}\end{array}$ & $\begin{array}{l}\stackrel{0}{i n} \\
\dot{y}\end{array}$ & $\underset{\substack{\circ \\
\infty \\
\infty \\
i n}}{ }$ & i & 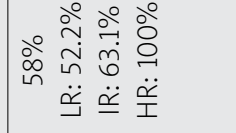 & 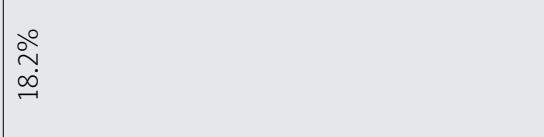 & ํำ \\
\hline 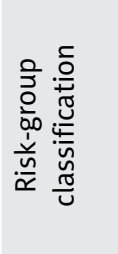 & 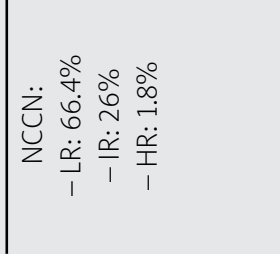 & 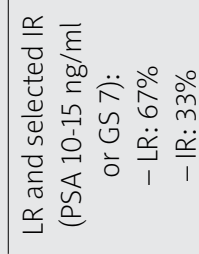 & 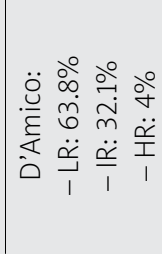 & 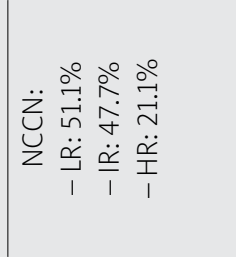 & 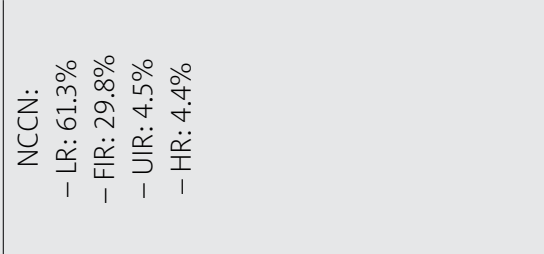 & 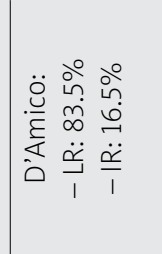 \\
\hline 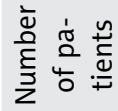 & $\stackrel{\tilde{\vartheta}}{\sim}$ & 苫 & $\stackrel{ \pm}{\lesssim}$ & $\stackrel{゚}{\stackrel{2}{f}}$ & $\begin{array}{l}\sigma \\
\infty \\
o \\
- \\
-\end{array}$ & $\underset{\sim}{\stackrel{\text { ৷ }}{ }}$ \\
\hline 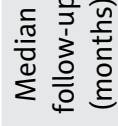 & 6 & $\tilde{m}$ & $\stackrel{2}{\gtrless}$ & $\begin{array}{l}\circ \\
\text { ñ }\end{array}$ & $\begin{array}{l}0 \\
-1 \\
\infty\end{array}$ & a \\
\hline 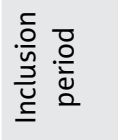 & 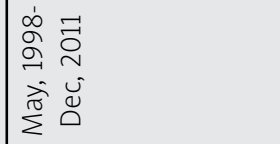 & 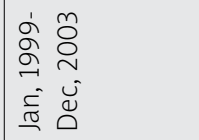 & 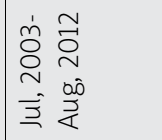 & 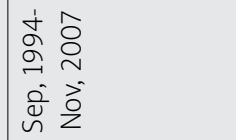 & $\begin{array}{l}\dot{\alpha} \hat{\circ} \\
\text { ò }\end{array}$ & 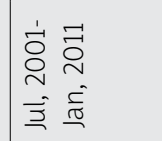 \\
\hline 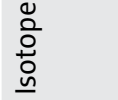 & \begin{tabular}{|l}
$\bar{D}$ \\
$\stackrel{0}{0}$ \\
$\stackrel{0}{a}$
\end{tabular} & $\bar{\Xi}$ & $\bar{\Xi}$ & $\bar{\Xi}$ & $\bar{\Xi}$ & $\bar{\Xi}$ \\
\hline 章 & 导 & 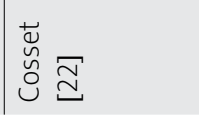 & 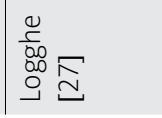 & 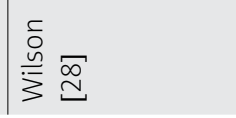 & 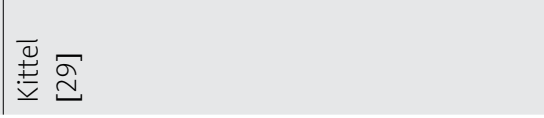 & 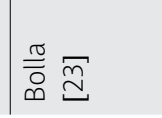 \\
\hline
\end{tabular}




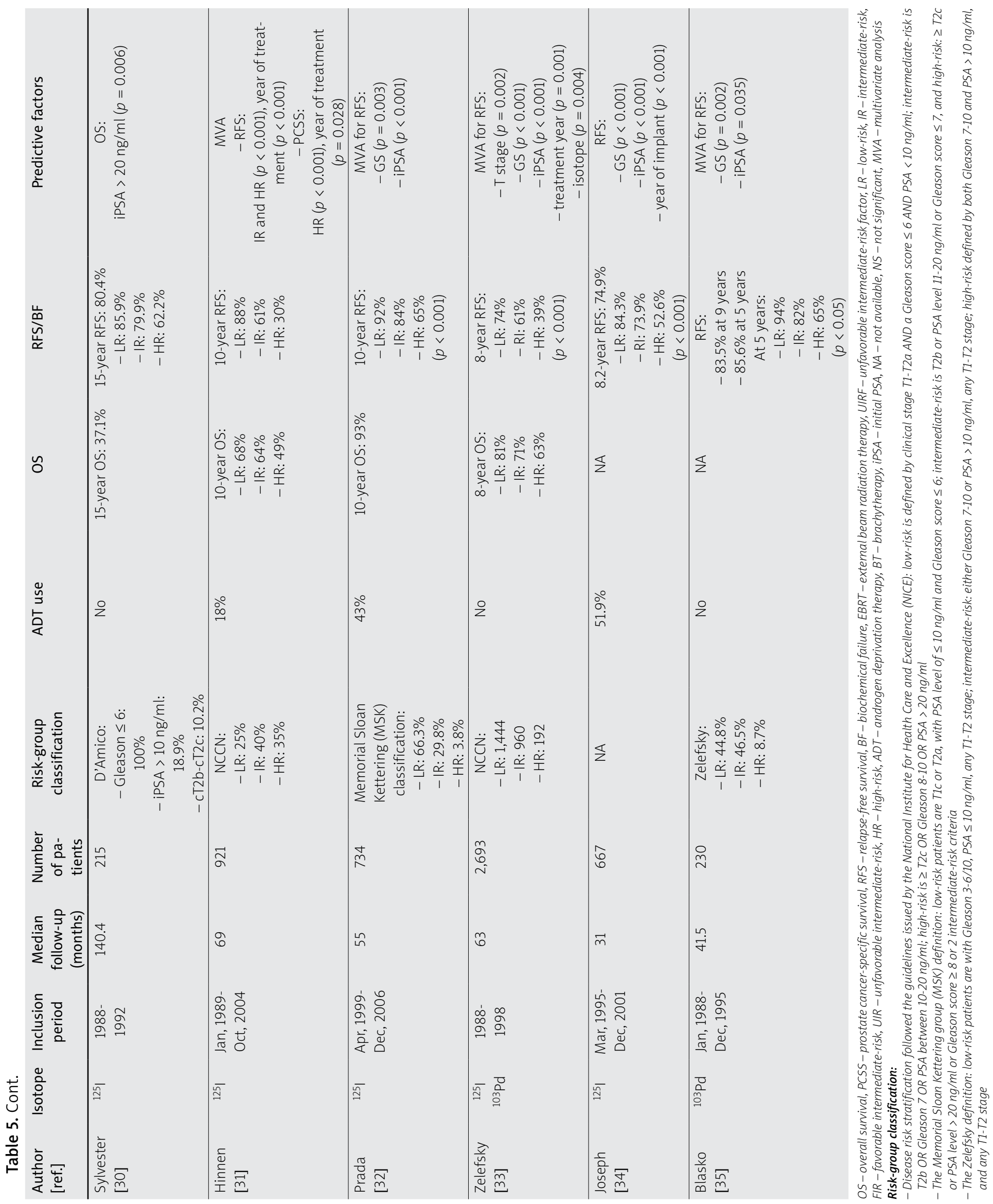




\section{References}

1. Mottet 2018, http://uroweb.org/guidelines/compilations-of-all-guidelines/

2. Slevin F, Sethugavalar B, Al-Qaisieh B et al. Ten-year longitudinal health-related quality of life following iodine-125 brachytherapy monotherapy for localized prostate cancer. J Contemp Brachytherapy 2020; 12: 540-546.

3. Cosset J, Gomme S, Peiffert D et al. Clinical and dosimetric analysis of 469 prostate cancer patients treated in France in 2005 by permanent implant brachytherapy using the Iodin 125 seeds IsoSeed Bebig: report to the French Economic committee of health products (CEPS). Cancer/Radiothérapie 2007; 11: 206-213.

4. Salomon L, Azria D, Bastide C et al. Recommendations OncoUrology 2010: Prostate cancer. Progrès en Urologie 2010; 20 Suppl. 4: S217-S252.

5. Heindenreich A, Bastian PJ, Bellmunt J et al. EAU Guidelines on Prostate Cancer. Part 1: Screening, Diagnosis, and Local Treatment with Curative Intent - Update 2013. Eur Urol 2014; 65: 124-137.

6. Davis B, Horwitz E, Lee W et al. American Brachytherapy Society consensus guidelines for transrectal ultrasound-guided permanent prostate brachytherapy. Brachytherapy 2012; 11: 6-19.

7. Frank S, Grimm P, Sylvester J et al. Interstitial implant alone or in combination with external beam radiation therapy for intermediate-risk prostate cancer: A survey of practice patterns in the United States. Brachytherapy 2007; 6: 2-8.

8. Chin J, Rumble RB, Kollmeier M et al. Brachytherapy for patients with prostate cancer: American Society of Clinical Oncology/Cancer Care Ontario Joint Guideline Update. J Clin Oncol 2017; 35: 1737-1745.

9. NCCN Guidelines Version 4.2018 Prostate Cancer. https:// www.ncen.org.

10. Zumsteg Z, Spratt D, Pei I et al. A new risk classification system for therapeutic decision making with intermediate-risk prostate cancer patients undergoing dose-escalated external-beam radiation therapy. Eur Urol 2013; 64: 895-902.

11. Podder T, Beaulieu L, Caldwell B et al. AAPM and GECESTRO guidelines for image-guided robotic brachytherapy: Report of Task Group 192. Med Phys 2014; 41: 101501.

12. Roach M, Hanks G, Thames H et al. Defining biochemical failure following radiotherapy with or without hormonal therapy in men with clinically localized prostate cancer: Recommendations of the RTOG-ASTRO Phoenix Consensus Conference. Int J Radiat Oncol Biol Phys 2006; 65: 965-974.

13. Hennequin C, Cormier L, Richaud P et al. Curiethérapie exclusive du cancer de la prostate par implants permanents: Indications et résultats. Revue du CC-AFU. Prog Urol 2013, 23: 378-385.

14. Tran AT, Mandall P, Swindell R et al. Biochemical outcomes for patients with intermediate risk prostate cancer treated with I-125 interstitial brachytherapy monotherapy. Radiother Oncol 2013; 109: 235-240.

15. Herbert C, Morris W, Keyes M et al. Outcomes following iodine- 125 brachytherapy in patients with Gleason 7 , intermediate risk prostate cancer: a population-based cohort study. Radiother Oncol 2012; 103: 228-232.

16. Munro N, Al-Qaisieh B, Bownes P et al. Outcomes from Gleason 7, intermediate risk, localized prostate cancer treated with Iodine-125 monotherapy over 10 years. Radiother Oncol 2010; 96: 34-37.

17. Berlin A, Moraes F, Sanmamed $\mathrm{N}$ et al. International multicenter validation of an intermediate risk subclassification of prostate cancer managed with radical treatment without hormone therapy. J Urol 2019; 201: 284-290.
18. Frank S, Pugh T, Blanchard P et al. Prospective phase 2 trial of permanent seed implantation prostate brachytherapy for intermediate-risk localized prostate cancer: efficacy, toxicity, and quality of life outcomes. Int J Radiat Oncol Biol Phys 2018; 100: 374-382.

19. Routman D, Funk R, Stish B et al. Permanent prostate brachytherapy monotherapy with I-125 for low- and intermediate-risk prostate cancer: Outcomes in 974 patients. Brachytherapy 2019; 18: 1-7.

20. Chao M, Spencer S, Guerrieri $M$ et al. A single institution analysis of low-dose-rate brachytherapy: 5-year reported survival and late toxicity outcomes. J Contemp Brachytherapy 2018; 10: 155-161.

21. Peacock M, Martell K, Taggar A. Institutional long-term outcomes at the first Canadian center performing intraoperatively planned low-dose-rate brachytherapy alone in lowand intermediate-risk prostate cancer. Brachytherapy 2017; 16: 822-830.

22. Cosset J, Flam T, Belin L et al. Long-term results of permanent implant prostate cancer brachytherapy: A single-institution study of 675 patients treated between 1999 and 2003. Cancer Radiother 2016; 20: 261-267.

23. Bolla M, Verry C, Giraud JY et al. Results of a cohort of 200 hormone-naïve consecutive patients with prostate cancer treated with iodine 125 permanent interstitial brachytherapy by the same multidisciplinary team. Cancer Radiother 2014; 18: 643-648.

24. Tom M, Reddy C, Smile T et al. Validation of the NCCN prostate cancer favorable- and unfavorable-intermediate risk groups among men treated with I-125 low dose rate brachytherapy monotherapy. Brachytherapy 2020; 19: 43-50.

25. Langley SEM, Soares R, Uribe J et al. Long term oncological outcomes and toxicity in 597 men aged $\leq 60$ years at time of low-dose-rate brachytherapy for localised prostate cancer. BJU Int 2018; 121: 38-45.

26. Fellin G, Mirri M, Santoro L et al. Low dose rate brachytherapy (LDR-BT) as monotherapy for early stage prostate cancer in Italy: Practice and outcome analysis in a series of 2237 patients from 11 institutions. Br J Radiol 2016; 89: 20150981.

27. Logghe P, Verlinde R, Bouttens F. Long term outcome and side effects in patients receiving low-dose I125 brachytherapy: a retrospective analysis. Int Braz J Urol 2016; 42: 906-917.

28. Wilson C, Waterhouse D, Lane SE. Ten-year outcomes using low dose rate brachytherapy for localised prostate cancer: An update to the first Australian experience. J Med Imaging Radiat Oncol 2016; 60: 531-538.

29. Kittel J, Reddy C, Smith K et al. Long-term efficacy and toxicity of low-dose-rate 125I prostate brachytherapy as monotherapy in low-, intermediate-, and high-risk prostate cancer. Int J Radiat Oncol Biol Phys 2015; 92: 884-893.

30. Sylvester J, Grimm P, Wong J et al. Fifteen-year biochemical relapse-free survival, cause-specific survival, and overall survival following I125 prostate brachytherapy in clinically localized prostate cancer: Seattle experience. Int J Radiat Oncol Biol Phys 2011; 81: 376-381.

31. Hinnen K, Battermann J, Van Roermund J et al. Long-term biochemical and survival outcome of 921 patients treated with I-125 permanent prostate brachytherapy. Int J Radiat Oncol Biol Phys 2010; 76: 1433-1438.

32. Prada P, Juan G, González-Suárez et al. Prostate-specific antigen relapse-free survival and side-effects in 734 patients with up to 10 years of follow-up with localized prostate cancer treated by permanent 125-iodine implants. BJU Int 2010; 106: 32-36.

33. Zelefsky MJ, Kuban DA, Levy LB et al. Multi-institutional analysis of long-term outcome for stages T1-T2 prostate cancer treated with permanent seed implantation. Int J Radiat Oncol Biol Phys 2007; 67: 327-333. 
34. Joseph J, Al-Qaisieh B, Ash D et al. Prostate-specific antigen relapse-free survival in patients with localized prostate cancer treated by brachytherapy. BJU Int 2004; 94: 1235-1238.

35. Blasko J, Grimm P, Sylvester J et al. Palladium-103 brachytherapy for prostate carcinoma. Int J Radiat Oncol Biol Phys 2000; 46: 839-850.

36. Burdick M, Reddy C, Ulchaker J et al. Comparison of biochemical relapse-free survival between primary Gleason score 3 and primary Gleason score 4 for biopsy Gleason score 7 prostate cancer. Int J Radiat Oncol Biol Phys 2009; 73: 14391445.

37. Kindts I, Stellamans K, Billiet I et al. 125I brachytherapy in younger prostate cancer patients : Outcomes in low- and intermediate-risk disease. Strahlenther Onkol 2017; 193: 707-713.

38. Nurani R, Wallner K, Merrick G et al. Optimized prostate brachytherapy minimizes the prognostic impact of percent of biopsy cores involved with adenocarcinoma. J Urol 2007; 178: 1968-1973.

39. Rossi P, Clark P, Papagikos M et al. Percentage of positive biopsies associated with freedom from biochemical recurrence after low-dose-rate prostate brachytherapy alone for clinically localized prostate cancer. Urology 2006; 67: 349-353.

40. Guzzo T, Levin B, Lee R et al. Relationship of biochemical outcome to percentage of positive biopsies in men with clinically localized prostate cancer treated with permanent interstitial brachytherapy. Urology 2008; 71: 723-727. 